\title{
VARIAÇÕES SEMÂNTICAS NO (DES)USO DO CLÍTICO SE NO PORTUGUÊS FALADO EM VITÓRIA DA CONQUISTA
}

\section{SEMANTIC VARIATIONS IN THE (DIS)USE OF THE CLITIC SE IN SPOKEN PORTUGUESE IN VITÓRIA DA CONQUISTA}

\author{
Jodalmara Oliveira Rocha Teixeira ${ }^{1}$ \\ Jorge Augusto Alves da Silva ${ }^{2}$ \\ Universidade Estadual do Sudoeste da Bahia (UESB)
}

\begin{abstract}
RESUMO
Neste artigo, objetivamos descrever as variações semânticas no (des)uso do clítico SE, em estruturas tradicionalmente classificadas como reflexivas, na fala vernácula de Vitória da Conquista - BA. Tais variações atuam como indícios de trajetória de mudança, que fazem com que o SE caminhe da função original de clítico reflexivo para a categoria de afixo verbal, via gramaticalização. Para testar essa hipótese, analisamos dados extraídos dos corpora orais PPVC (Corpus do Português Popular de Vitória da Conquista) e PCVC (Corpus do Português Culto de Vitória da Conquista), baseados nos pressupostos da Sociolinguística Variacionista e do Sociofuncionalismo. Os nossos resultados evidenciaram a preferência dos conquistenses pelo emprego do clítico ao seu apagamento. Quanto ao condicionamento linguístico, a presença do SE revelou-se sensível ao tipo de clítico e à classe semântica do verbo. Relativamente ao condicionamento social, verificamos que o uso do SE é mais favorecido entre os informantes mais escolarizados e da faixa etária intermediária.
\end{abstract}

PALVRAS-CHAVE: Clítico SE. Vitória da Conquista. Variação Linguística.

\begin{abstract}
In this paper, we aim to describe the semantic variations in the (dis) use of the clitic SE, in structures traditionally classified as reflexive, in the vernacular speech of Vitória da Conquista$\mathrm{BA}$. Such variations act as signs of change trajectory, causing the SE to move from the original function of reflexive clitic to the category of verbal affix, through grammaticalization. To test this hypothesis, we analyze data extracted from the oral corpora PPVC (Corpus do Português Popular de Vitória da Conquista), and PCVC (Corpus do Português Culto de Vitória da Conquista), based on the postulates of Labovian Variationist Sociolinguistics and Sociofuncionalism. Our results evidenced the preference of the conquistenses for the use of the clitic, instead of deleting it. As for linguistic conditioning, the presence of SE was sensitive to the type of clitic and to the semantic class of the verb. Regarding social conditioning, we found that the use of SE is more favored among the more educated informants and in the middle age group.
\end{abstract}

KEYWORDS: Clitic SE. Vitória da Conquista. Linguistic Variation.

\footnotetext{
${ }^{1}$ Mestre em Linguística pela Universidade Estadual do Sudoeste da Bahia (UESB). Professora efetiva da área de Linguagens do Colégio Estadual Renato Viana (SEC - BA).

2 Doutor em Letras (área de concentração em Linguística Histórica) pela Universidade Federal da Bahia (UFBA). Professor titular da Área de Linguística e Língua Portuguesa do Departamento de Estudos Linguísticos e Literários (DELL) da Universidade Estadual do Sudoeste da Bahia (UESB).
} 


\section{INTRODUÇÃO}

Tradicionalmente integrado ao quadro dos pronomes pessoais reflexivos (cf. CUNHA, 1986; ROCHA LIMA, 2003; BECHARA, 2004), o clítico SE, desde sua origem latina, exclusivamente reflexiva, vem assumindo diferentes funções (indicar reflexividade ou reciprocidade, apassivar, indeterminar, detematizar a posição do sujeito, exprimir espontaneidade ou envolvimento do sujeito etc.) ao longo de sua trajetória na história da Língua Portuguesa do Brasil. Indiferentes a esse processo, as gramáticas tradicionais continuam a tratar as construções de SE com o mesmo conservadorismo e ortodoxia com que sempre abordaram o tema, a despeito das mudanças sofridas pelo item no Português do Brasil (doravante PB).

Autores como Monteiro (1994), Ilari et al. (2002) e Castilho (2016), por exemplo, sublinham que, no PB, diferentemente do que pressupõe a Gramática Tradicional, as estruturas ditas reflexivas não se limitam ao âmbito da reflexividade; esta é apenas uma das variadas possibilidades de análise de tais construções. Ademais, não obstante tenha ampliado os seus domínios funcionais ${ }^{3}$ para além da correferencialidade entre sujeito e objeto, o clítico SE apresenta, ainda, outra peculiaridade. Em relação à sua realização lexical no PB contemporâneo, conforme estudo realizado por Oliveira (2006), o SE pode ser: a) suprimido (01); b) neutralizado na forma da $3^{a}$ pessoa (02); c) inserido (03) e d) "duplicado" (04). Vejamos, abaixo, exemplos transcritos da pesquisadora:

(01) Eu $\varnothing$ conformei com a decisão dele.

(02) Eu se conformei com a decisão dele.

(03) Ele se ressuscitou.

(04) Ele se conformou-se com a decisão dele.

Segundo Oliveira (2006), o apagamento do SE parece ser uma característica do falar mineiro, a neutralização é um fenômeno pambrasileiro e a inserção, bem como a "duplicação" do SE é um fenômeno nordestino.

Motivados por essas peculiaridades, é nosso objetivo, neste artigo, analisar e descrever, à luz dos postulados da Sociolinguística Variacionista e do Sociofuncionalismo ${ }^{4}$, as variações semânticas no (des)uso do clítico $\mathrm{SE}$, em estruturas tradicionalmente classificadas como reflexivas, na fala vernácula de Vitória da Conquista - BA. Tais variações podem ser consideradas indícios de trajetória de mudança, que fazem com que o SE caminhe da função original de pronome reflexivo para a categoria de afixo verbal, mediante processo de gramaticalização ${ }^{5}$ (cf.

\footnotetext{
${ }^{3}$ Empregamos o termo "domínio funcional” em conformidade com Givón (1984), em referência a áreas funcionais gerais como reflexividade, reciprocidade, passividade, indeterminação, ou a áreas mais estritas, como os valores sintático e semântico assumidos pelas formas SE/ $\varnothing$ ao longo do tempo.

${ }^{4}$ No tocante à teoria sociofuncionalista, para fins de esclarecimento, julgamos oportuno valermo-nos das palavras de Tavares (2013, p. 28-38): "Desde o final dos anos 80, uma orientação de pesquisa que pode ser denominada ‘sociofuncionalismo’ vem se dedicando à investigação de fenômenos de variação e de mudança linguística, buscando articular, para a análise e a explicação desses fenômenos, pressupostos teórico-metodológicos da sociolinguística variacionista e do funcionalismo linguístico norte-americano ou, em sua denominação mais recente, linguística baseada no uso. [...] Numa perspectiva sociofuncionalista, os resultados quantitativos e qualitativos obtidos são explicados através de princípios e motivações de natureza cognitivo-comunicativa - cuja fonte principal é o funcionalismo norte-americano ou linguística baseada no uso -, além de princípios e motivações de natureza sociocultural e estilística - cuja fonte principal é a sociolinguística variacionista".

5 Para Hopper \& Traugott (1993, p. 1), a gramaticalização é um processo em que "tanto itens lexicais e construções formam-se em certos contextos linguísticos para exercer funções gramaticais quanto itens gramaticais desenvolvem novas funções gramaticais". Em outras palavras, trata-se de "um conjunto de processos por que passa a palavra, durante os quais ( i ) ela ganha novas propriedades sintáticas, morfológicas, fonológicas e semânticas; ( ii ) transforma-se numa forma presa; ( iii ) e pode até mesmo desaparecer, como consequência de uma cristalização extrema" (CASTILHO, 2016, p. 138).
} 
BYBEE et al, 1994; HOPPER; TRAUGOTT, 1993). Para testar essa hipótese, analisamos dados empíricos de fala extraídos dos corpora PPVC e PCVC (Português Popular e Português Culto de Vitória da Conquista, respectivamente), constituídos pelo Grupo de Pesquisa em Linguística Histórica e em Sociofuncionalismo da Universidade Estadual do Sudoeste da Bahia - UESB.

No ensejo de cumprirmos o nosso propósito, estruturamos este artigo em três seções. Na primeira delas, intitulada OSE no PB: algumas considerações, apresentamos o fenômeno em estudo, questionando as incongruências da abordagem tradicional em detrimento do uso efetivo no PB. Em seguida, na seção O SE e sua natureza peculiar, discutimos aspectos relacionados ao estatuto categorial do SE. Por fim, na terceira seção, denominada O comportamento do SE em Vitória da Conquista, apresentamos os resultados de nossa análise, cotejando-os com os de autores como D’Albuquerque (1988), Nunes (1995), Freitag (2003), Camacho (2003) e Mello (2009), que também se dedicaram ao estudo do SE dito reflexivo no PB. Os principais achados da pesquisa e suas contribuições para a descrição do PB contemporâneo são resumidos nas Considerações finais.

\section{O SE no PB: algumas considerações}

Fruto do desenvolvimento dos estudos linguísticos empreendidos nos últimos anos, sobretudo ao longo da segunda metade do século XX, o SE tem sido perspectivado como uma unidade pertencente ao conjunto dos clíticos, mais precisamente dos clíticos especiais ${ }^{6}$. Apesar de não possuir autonomia prosódica e distribucional, o clítico exibe comportamentos diversos nas várias estruturas em que ocorre e, por isso, sua descrição continua sendo assumida como um desafio atual e de interesses múltiplos.

A aptidão do pronome clítico SE para transmudar-se tem dado margem a estudos que abordam, principalmente, problemas relacionados à passivização, à indeterminação do agente e à reflexivização, três de suas nuanças mais frequentes. Quaisquer que sejam os desdobramentos de tais estudos, todos sinalizam as incongruências da Gramática Tradicional ao tratar do tema. Imprecisões conceituais e confusões terminológicas nos causam, ainda, certas dúvidas quanto, por exemplo, à diferença entre parte integrante do verbo, verbo essencialmente pronominal, verbo acidentalmente pronominal, elemento fossilizado - conceitos encontrados nas gramáticas tradicionais, com vistas a explicar a função reflexiva do SE.

Inspiradas no modelo de gramática do Latim Clássico ${ }^{7}$, as gramáticas tradicionais, assim como os manuais de língua portuguesa, caracterizam o fenômeno da reflexividade, basicamente, como a inversão da transitividade da ação verbal. Ou seja, a ação expressa pelo verbo não passa para uma outra pessoa $(A \rightarrow B)$; reverte-se à pessoa do próprio sujeito $(A \rightarrow A)$, que é, simultaneamente, agente e alvo dessa ação. Destarte, uma construção reflexiva poderia ser assim esquematizada: $\left[\mathrm{SN}_{1}+\mathrm{V}+\mathrm{SN}_{1}\right]^{8}$. Todavia, como demonstraremos adiante, não é tão simples assim.

Ao nos debruçar sobre os outros reflexivos, podemos perceber que me, te, nos, vos podem funcionar como complementos de um verbo transitivo, ao passo em que são correferenciais ao sujeito da oração. Por outro lado, também podem ser complementos de um verbo transitivo, sem exibir o traço de correferencialidade. Observem-se os exemplos, de nossa autoria:

(05) Eu me arrumei cuidadosamente. $\left[\mathrm{SN}_{1}+\mathrm{V}+\mathrm{SN}_{1}\right]$

\footnotetext{
${ }^{6}$ Uma definição do termo "clíticos especiais" será apresentada posteriormente.

7 Mattos e Silva (1989) advoga que a Gramática Tradicional espelha-se, sobretudo, nos estudos de Platão (V-IV a.C.), de Dionísio da Trácia (II a.C.), de Varrão (I a.C.), de Quintiliano (I d.C.), de Donato (IV d.C.) e de Prisciano (V d.C.). Esses eram os escritores que, na visão da pesquisadora, serviram de modelo para a consolidação de regras que configurariam a variedade linguística de maior prestígio social. Por esse prisma, sublinha a autora, determina-se que os modelos de reflexão sobre a língua portuguesa sejam os latinos, mormente por serem fornecidos pelo que ela chama de Tradição Gramatical - posicionamento que também assumimos neste estudo.

8 O índice " 1 " expressa a correferencialidade entre sujeito e objeto.
} 
(06) Maria me arrumou cuidadosamente. $\left[\mathrm{SN}_{1}+\mathrm{V}+\mathrm{SN}_{2}\right]$

Não obstante, no quadro pronominal, o pronome de terceira pessoa funciona apenas como reflexivo, de sorte que toda vez que surge como complemento de um verbo transitivo, será, obrigatoriamente, correferente ao sujeito da oração, como em (07):

(07) Maria se arrumou cuidadosamente $\left[\mathrm{SN}_{1}+\mathrm{V}+\mathrm{SN}_{1}\right]$.

O esquema descrito acima, contudo, não se aplica a qualquer construção de Língua Portuguesa que pretenda expressar reflexividade. O esforço de singularizar os fenômenos da língua por meio de esquemas ou fórmulas nem sempre logra êxito, posto que esbarra na impossibilidade de contemplar outros tantos usos, comuns aos nossos vernáculos. À guisa de exemplificação do que ora afirmamos, consideremos as construções a seguir, por nós elaboradas:

(08) Ele se suicidou.

(09) Os irmãos se abraçaram.

(10) As árvores se agitam com o vento.

(11) Essa estrada se estende para além daquele morro.

(12) Você se aborrece à toa.

(13) Vocês precisam se levantar bem cedinho amanhã.

Segundo os preceitos das gramáticas tradicionais, seria lícito dizer que todas essas construções se encaixam no esquema: $\left[\mathrm{SN}_{1}+\mathrm{V}+\mathrm{SN}_{1}\right]$. $\mathrm{O}$ fenômeno da reflexividade, no entanto, é muito mais complexo do que sugere a tradição gramatical e, longe de ser simplificado através de fórmulas, abrange vários tipos de $\mathrm{SE}$, entre os quais o grupo daqueles que exprimem a voz média ou medial ${ }^{9}$ (cf. CAMACHO, 2007).

Empregado sempre com verbos transitivos, o SE reflexivo manteve, em suas linhas gerais (cf. CARVALHO, 1990), a mesma feição sintática herdada da matriz latina, a saber, complemento objetivo direto ou indireto. O SE recíproco, cujo uso também está presente no Português atual, é empregado para indicar que a ação é mútua entre dois ou mais indivíduos, e equivale à expressão um ao outro, como em (09): Os irmãos se abraçaram (um ao outro).

Em construções como em (13), mesmo o clítico retomando a pessoa do sujeito, tomando-o como ponto de partida da ação verbal, este sempre veicula um envolvimento e integração no evento que nele mesmo se encerra, e não funciona como o objeto sobre o qual recairiam os efeitos da ação. Diferentemente do que ocorre com as estruturas reflexivas e recíprocas, nas construções com esse tipo de SE, o verbo sofre alteração de sentido, caso o clítico seja substituído por um objeto não anafórico ao sujeito, conforme exemplificamos em (14):

(14) Pedro o levantou.

Fica claro que o sentido da oração passa a ser "Pedro suspendeu algo / alguém", "Pedro ergueu algo / alguém". Assim sendo, o SE desempenha importante papel na interpretação verbal; remete ao sujeito, transmitindo a ideia de que ele se encontra integrado e interessado na ação expressa pelo verbo. Por isso, esse tipo de SE é chamado pela Gramática Tradicional de pronome reflexivo fossilizado, de pronome inerente ou de parte integrante do verbo.

\footnotetext{
9 A voz média, segundo Câmara Jr. (1974, p. 182-183), possui três subcategorias: medial reflexiva, medial recíproca e medial dinâmica. Ainda segundo o autor, eram valores presentes no latim clássico que foram transmitidos ao português. No entanto, as estruturas mediais, no decorrer do tempo, foram se diluindo em nossas gramáticas (cf. CAMACHO, 2003), deixando de ocupar o justo espaço nas seções destinadas à categoria de voz. Em alguns casos, elas são sumariamente mencionadas, porém, por se aproximarem estrutural e semanticamente das formas passivas, reflexivas e recíprocas, acabam não sendo devidamente descritas e caracterizadas nas gramáticas tradicionais.
} 
Talvez por não obrigar coindexação do SE com o sujeito, a medial dinâmica permitiu, "[...] no próprio latim clássico, o uso da reflexiva com sujeitos inanimados, envoltos aqui numa espécie de personificação metafórica" (CARVALHO, 1990, p. 67), abrindo espaço para orações como em (15) e $(16)^{10}$ :

(15) O mar se agita.

(16) A estrada se estende.

A medial dinâmica também deu origem à medial expletiva. O SE, nesse caso, contíguo a verbo intransitivo, tem valor mais estilístico do que propriamente gramatical e é chamado pela Gramática Tradicional de pronome ou particula de realce. Câmara Jr. (1986, p. 164) cita as construções ir-se, chegar-se, rir-se como representativas da medial expletiva.

Atualmente, são várias as possibilidades de construção com o SE que não desempenham a função reflexiva propriamente dita. Com o passar do tempo, o SE, antes restrito às funções de objeto direto e indireto no Latim, alarga seus domínios funcionais. Nesse percurso, o clítico foi, paulatinamente, assumindo outras nuanças, de modo que, ao vislumbrarmos as fronteiras entre as diversas funções por ele assumidas, acabamos nos deparando com a impossibilidade de se estabelecerem contornos bem definidos.

Ao lado da complexidade suscitada acima, há, ainda, outras controvérsias que, no decorrer dos tempos, têm permeado a análise dos clíticos. Uma delas diz respeito ao estatuto e à natureza do SE, aspectos que passamos a explorar na seção a seguir.

\section{O SE e sua natureza peculiar}

Por obra da ausência de consenso quanto ao estatuto e à natureza do SE, o item tem recebido diferentes designações (pronome, clítico, partícula, indice, simbolo, afixo) e, simultaneamente, diferentes propostas de classificação (reflexivo, reciproco, passivo, indeterminado, inerente, expletivo, ergativo, médio, oblíquo etc.). Sobrelevamos que, mesmo em nosso estudo, não há de se pôr fim ao problema, tampouco unificar terminologias. O nosso propósito é fazer uma reflexão analítica sobre o fenômeno dentro do escopo teórico pelo qual o observamos. Ademais, vale destacar que as considerações tecidas ao longo deste trabalho não se baseiam em um novo aporte teórico, mas, acima de tudo, numa nova metodologia que não era, nem de longe, aventada pelas gramáticas tradicionais.

Dito isto, apresentamos, a seguir, dois pontos de vista complementares que reúnem algum consenso na descrição do SE: um, mais tradicional, que o classifica como pronome pessoal reflexivo; outro, mais recente, que o assume como um dos clíticos do PB.

\subsection{Sob a ótica da pronominalidade}

É possível encontrar reflexões sobre o SE em antigos trabalhos de análise gramatical, como, por exemplo, na Grammatica da Lingua Portuguesa, de João de Barros (1540), ou em gramáticas de reconhecido mérito, mormente publicadas no século XIX. Em tais obras (e.g. BARBOZA, 1830; REIS, 1868; DIAS, 1881), sublinham-se a multifuncionalidade do SE e sua presença em estruturas diversas. Dias (1881, p. 110-111), por exemplo, ressalta essa polivalência ao relatar a ocorrência do SE em construções (i) reflexivas, (ii ) recíprocas, (iii) passivas e (iv ) impessoais. Nesses trabalhos, o SE é, por norma, pronome reflexivo.

De cunho tradicional, essa perspectiva de análise repercute, hodiernamente, em trabalhos amplamente divulgados e adotados em contextos pedagógicos, como as gramáticas de Bechara

${ }^{10}$ Exemplos transcritos de Carvalho (1990, p. 68). 
(1966) ou de Cunha (1986). No primeiro deles, “[...] a função inicial e própria do pronome se é, como em latim, a de reflexivo, isto é, faz refletir sobre o sujeito a ação que ele mesmo praticou" (BECHARA, 1966, p.313). Em Cunha (1986, p.282-283), o SE é um pronome reflexivo “[...] quando o objeto direto ou indireto representa a mesma pessoa ou a mesma coisa que o sujeito do verbo [...]", ou um pronome recíproco, quando indica "que a ação é mútua entre dois ou mais indivíduos" (CUNHA, 1986, p.282-283).

Com base no estatuto pronominal do SE, esses autores explicam que o pronome pode funcionar como: ( i ) objeto direto (emprego mais comum); ( ii ) objeto indireto; ( iii ) sujeito de um infinitivo; ( iv ) pronome apassivador; ( $\mathrm{v}$ ) simbolo de indeterminação do sujeito (junto à 3 . $^{\text {a }}$ pessoa do singular de verbos intransitivos, ou de transitivos tomados intransitivamente); ( vi ) palavra expletiva (para realçar, com verbos intransitivos, a espontaneidade de uma atitude ou de um movimento do sujeito) e ( vii ) parte integrante de certos verbos que geralmente exprimem sentimento, on mudança de estado (cf. CUNHA, 1986, p.303-304). Mesmo que em algumas gramáticas tradicionais sejam identificados os principais usos e valores do SE, elas não fornecem uma caracterização ampla do item, que faça jus aos nossos vernáculos ${ }^{11}$. Em conjunto, as propriedades fonológicas, morfológicas e sintático-semânticas do SE continuam por explorar.

Em contrapartida, nas últimas décadas do século XX, começaram a surgir vários trabalhos nos quais se analisa o comportamento do SE no âmbito da cliticidade. Na próxima subseção, tecemos breves considerações sobre esse olhar, mantendo o nosso foco na análise do SE enquanto clítico especial.

\subsection{Sob a ótica da cliticidade}

O interesse na caracterização do SE enquanto clítico assumiu particular relevo a partir da segunda metade do século XX, quando começaram a ganhar força os estudos sobre os clíticos, instigados pelos trabalhos pioneiros de Kayne (1975) e de Zwicky (1977). Ambos propõem a delimitação, análise e descrição de um grupo de palavras incapazes de ocorrer isoladamente e que, por isso, precisam do apoio de palavras hospedeiras. No que respeita à Língua Portuguesa, integram o conjunto dos clíticos artigos, preposiçoes, conjunções e pronomes pessoais átonos (cf. BRITO, DUARTE e MATOS, 2003[1893]). Tradicionalmente situado entre estes últimos, o SE é assumido como um dos clíticos do PB.

Respaldadas em Zwicky (1977), Brito, Duarte e Matos (2003[1983], p.828-830), estabelecem a distinção entre clíticos especiais (pronomes pessoais átonos) e clíticos simples (artigos, preposições e conjunções). Essa diferença, segundo as autoras, se deve a dois fatos: (i ) os pronomes clíticos dependem, especificamente, do acento do verbo; já os clíticos simples se cliticizam a qualquer palavra que lhes siga, e ( ii ) os artigos, preposições e conjunções sempre precedem as palavras que os acolhem; os pronomes, em contrapartida, não têm uma posição fixa em relação ao verbo, podem precedê-lo (próclise), segui-lo (ênclise) ou ocorrer em seu interior (mesóclise).

Em sua tese de doutoramento intitulada Os pronomes clíticos do PB contemporâneo na perspectiva teórica da Morfologia Distribuida, Pereira (2006, p.1) descreve os clíticos pronominais como

\footnotetext{
objetos estruturalmente simples [...] que existem nas línguas naturais. Estes pequenos objetos deleitam e infernizam os linguistas que se aventuram a encará-los. No universo das línguas românicas, tanto o deleite quanto o inferno decorrem de três propriedades fundamentais por eles apresentadas [...]:

(i) Pronomes clíticos são fonologicamente deficientes e, por isso, são obrigatoriamente adjungidos a um hospedeiro.
} 11 O termo "vernáculos" é por nós utilizado em referência às variedades popular e culta da Língua Portuguesa do
Brasil, que caracterizam determinada comunidade linguística e que, portanto, constituem o uso real da língua. 
(ii) O hospedeiro do clítico pronominal tem que ser necessariamente verbal.

(iii) Os pronomes clíticos em geral não apresentam ordem fixa em relação aos seus hospedeiros.

A cliticização ${ }^{12}$ pronominal particulariza o Português entre as outras línguas românicas, sobretudo, quando comparadas as variedades brasileira e europeia. De acordo com Pereira (2006), no mínimo, dois aspectos visíveis se relacionam a essa particularidade: ( i ) o reduzido número de clíticos na gramática nuclear ${ }^{13}$ do $\mathrm{PB}$ contemporâneo e (ii ) o predomínio da próclise, independentemente do contexto de realização clítica.

Feitas essas breves considerações acerca da natureza peculiar do SE, passamos, na próxima seção, a apresentar a análise e discussão dos resultados obtidos.

\section{O comportamento do SE em Vitória da Conquista}

Neste estudo, analisamos dados extraídos das 48 entrevistas que compõem os dois corpora orais, constituídos pelo Grupo de Pesquisa em Linguística Histórica e em Sociofuncionalismo, estratificados quanto ao sexo (masculino/feminino), tempo de escolarização (in formantes menos escolarizados - com até 4 anos de escolarização/informantes mais escolarizados - com 11 anos ou mais de escolaridade) e faixa etária dos informantes (Faixa I: de 15 a 35 anos; Faixa II: de 36 a 49 anos; Faixa III: de 50 anos em diante).

Ao todo, foram identificadas 617 situações linguísticas nas quais o clítico SE ocorre ou deixou de ocorrer. Em função da variável dependente - presença e apagamento do SE -, esses dados foram submetidos ao Programa Goldvarb X (SANKOFF; TAGLIAMONTE; SMITH, 2005). Entre os fatores controlados, quatro foram selecionados como relevantes, com nível de significância de $\mathbf{0 . 0 0 6}$ e input de $\mathbf{0 . 8 5}$, nesta ordem: (i ) escolaridade; (ii ) tipos de SE; (iii ) faixa etária e (iv) classe semântica do verbo. Destarte, apresentamos e discutimos os resultados referentes a essas variáveis, após exibirmos, a partir da Tabela 1, a seguir, o panorama geral da distribuição dos dados nos corpora.

\begin{tabular}{ccc}
\hline Emprego do Clítico & Apl/Total & \% \\
\hline Presença & $489 / 617$ & $79,3 \%$ \\
Apagamento & $128 / 617$ & $20,7 \%$ \\
\hline
\end{tabular}

Tabela 1 - Presença e Apagamento do clítico SE em Vitória da Conquista

Fonte: Elaboração da pesquisadora

Das 617 ocorrências coletadas, conforme se visualiza na Tabela 1, 489 apresentaram o clítico adjungido ao verbo, enquanto que, em 128, ele foi apagado. Em valores percentuais, esses números equivalem a 79,3\% de presença contra 20,7\% de ausência do clítico, confirmando, assim, a nossa expectativa de preenchimento do pronome.

Muito frequentemente, os trabalhos dedicados ao estudo do SE apontam uma tendência geral ao apagamento do clítico no $\mathrm{PB}$, como em pesquisas desenvolvidas por D'Albuquerque (1988), Nunes (1995) e Rocha (1999), por exemplo, na região Sudeste do país. Em outras regiões, no entanto, o movimento é inverso: o uso do clítico se mantém, ao passo em que se estende a contextos diversos, conforme apontam Freitag (2003), para a cidade sulista de Florianópolis, e

\footnotetext{
12 Processo de ligação do clítico ao seu hospedeiro, nos termos de Martins (2013, p.2231).

${ }_{13}$ Nos termos de Chomsky (1986), a gramática nuclear é uma noção estreitamente relacionada ao conceito de língua interna e corresponde ao estágio de língua-I de um adulto. Em outras palavras, refere-se a um momento relativamente estável da faculdade da linguagem, resultante do processo de parametrização da GU (Gramática Universal) em uma língua específica. A GU, por seu turno, corresponde ao estado inicial da faculdade da linguagem. Em relação às formas clíticas, a gramática nuclear do $\mathrm{PB}$ contemporâneo conta, segundo a autora, com quatro delas: me, te, se e the.
} 
Mello (2009), para a cidade nordestina de João Pessoa, cujos resultados gerais assemelham-se aos nossos.

Por meio de um estudo empírico, Freitag (2003) constatou, em Florianópolis, uma alta frequência de uso do SE em contextos outros, além dos já fixos. A pesquisadora atribui esse fenômeno à perda de clareza semântica nas construções com SE, num processo de gramaticalização que pode ser assim resumido: primeiro passo $\rightarrow$ o SE funciona, inicialmente, como marcador de entrada e mudança de tópicos; segundo passo $\rightarrow$ é reanalisado como afixo verbal; terceiro passo $\rightarrow$ seu uso é generalizado para outros contextos.

Também contrariando a tendência geral do $\mathrm{PB}$, a frequência de uso do SE dito reflexivo no português falado em João Pessoa - Paraíba, conforme constatou Mello (2009), é de 85\%, contra apenas $15 \%$ de apagamento. Assim como a pesquisadora, postulamos que essa tendência de o clítico SE ser amplamente apagado em determinadas regiões e mantido em outras pode se tratar de um caso de gramaticalização. Ao ser exaustivamente usado, o SE ganha uma frequência bastante expressiva, o que ocasiona o seu desgaste até atingir o grau zero do processo, ou seja, o desaparecimento. Tanto a manutenção como o apagamento refletem momentos distintos da trajetória do SE, constituindo, assim, estágios do seu processo de mudança, no qual a repetição possui um papel primordial. Ancorados em Bybee e coautores (1994), explicamos: determinada sequência de morfemas ou palavras, quando frequentemente utilizada, automatiza-se como uma única unidade no processamento. Essa alta frequência de uso leva à reanálise. Surge, então, uma nova estrutura, desencadeada pelo rearranjo das fronteiras entre os constituintes, assim especificada: $\left[\mathrm{Suj}_{\mathrm{i}}+\mathrm{pro}_{\mathrm{i}}+\right.$ verbo $]>\left[\mathrm{Suj}_{\mathrm{i}}+\left(\mathrm{pro}_{\mathrm{i}}+\right.\right.$ verbo $\left.)\right]$. Exemplificamos, a seguir, com dados dos nossos corpora.

(17) e aí se acha ... qué tudo e pode tudo, e nem sempre você pode. (ESP-PPVC-II-F)

(18) Até hoje nós sabe se virar. (JCS - PPVC - II -M)

(19) Aí, quando aquela água baxava, ficava aquelas marcas horríveis na parede, e a gente...claro, a gente era pequena, a minha mãe ia limpar com a vizinha que se tornou amiga da gente. (DFP-PCVC-I-F)

Os exemplos acima evidenciam que o SE, decategorizado, passa a se comportar, à semelhança de um afixo, como parte integrante do verbo: "seacha", "sevirar", "setornou", fato que se coaduna com o uso muito frequente de "selascar", "sefoder", comportando-se como verbos conjugados sem restrições, com todas as pessoas (considerando-se o atual quadro pronominal do PB), mormente na fala popular. Essas evidências corroboram a nossa hipótese de gramaticalização do SE, processo em que a forma migra da categoria inicial de pronome reflexivo e, mediante reanálise, passa a se especializar em funções cada vez mais gramaticalizadas. Por conseguinte, conforme nossa amostragem, o SE em Vitória da Conquista estaria obedecendo às etapas do cline de gramaticalização proposto por Hopper e Traugott (1993, p.103): item pleno > item gramatical $>$ clítico $>$ afixo. A etapa subsequente corresponde ao estágio final do percurso, quando o SE deixa de ocorrer na língua, como em algumas regiões do país, onde essa fase já se verifica. Entretanto, este não é, ainda, o caso da comunidade por nós investigada.

Dando prosseguimento à discussão, expomos, na subseção seguinte, os resultados das variáveis selecionadas, com base nos pesos relativos gerados pelo programa estatístico.

\subsection{Tipos de SE}

Em razão de envolver aspectos semânticos e também léxico-formais, a hipótese defendida para este grupo de fatores era a de que o uso do SE seria favorecido pelos clíticos que possuíssem mais valor informacional ou que fizessem parte da especificação lexical do verbo. Nessa perspectiva, os clíticos apresentariam a seguinte gradação: $S E$ reflexivo $>S E$ recíproco $>S E$ inerente 
$>S E$ indeterminador $>S E$ ergativo $>S E$ apassivador $>S E$ expletivo. De tal relação, o SE apassivador e o SE expletivo foram excluídos por knockout (ou nocaute ${ }^{14}$ ), de modo que o continuum hierárquico, agora, assim se expressa: $S E$ reflexivo $>S E$ reciproco $>S E$ inerente $>S E$ indeterminador $>S E$ ergativo. Os resultados dessa variável, expressos em pesos relativos, são apresentados no Gráfico 1 a seguir:

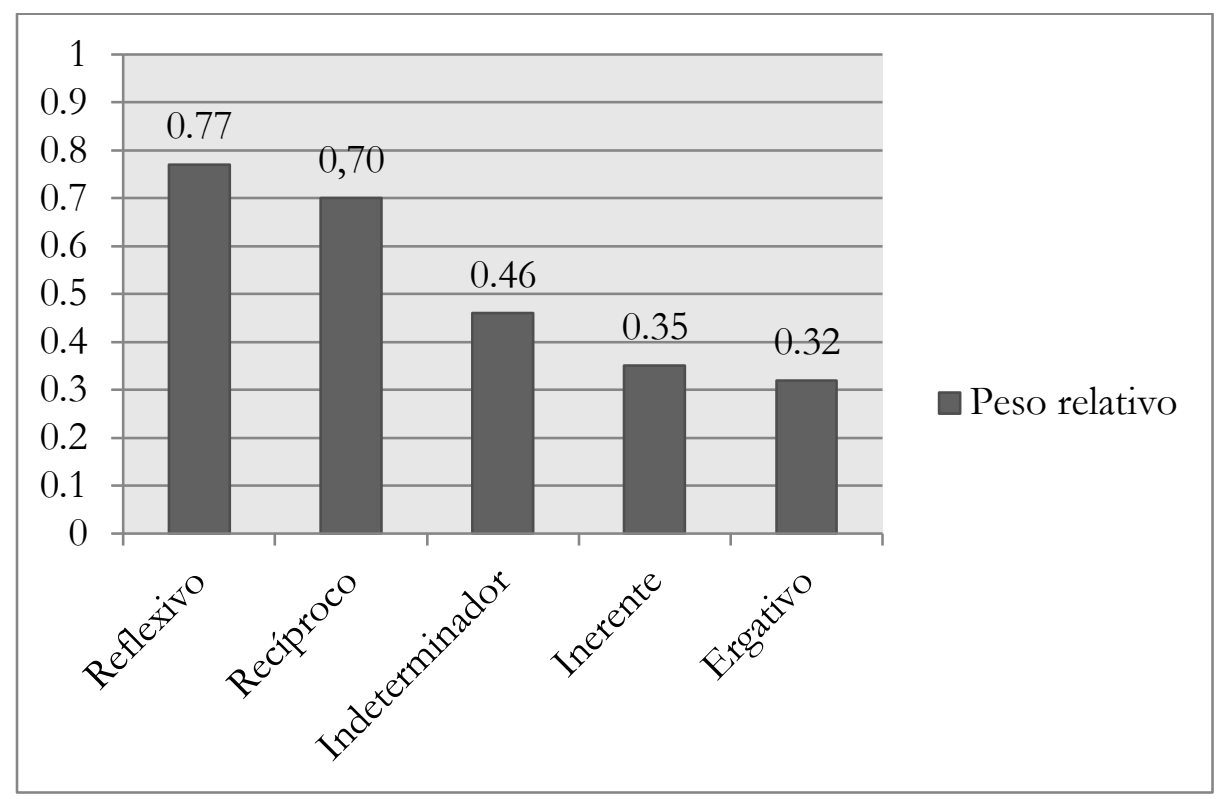

Gráfico 1 - Tipos de SE nos corpora PPVC e PCVC em pesos relativos Fonte: Elaboração da pesquisadora

Os resultados exibidos no Gráfico 1 indicam que os clíticos reflexivos e recíprocos, com pesos relativos de 0,77 e 0,70, respectivamente, são mais produtivos no falar conquistense. Posto que o peso relativo é a indicação do efeito que cada fator selecionado exerce sobre as variantes observadas, é interpretado como favorável, para uma variável binária, como em nosso estudo, se o valor obtido for superior a 0,50; como inibidor, se inferior a 0,50 e, como neutro, se igual a 0,50 (cf. SCHERRE; NARO, 2012). Por conseguinte, do ponto de vista estatístico, é lícito concluir, a partir dos resultados apontados no Gráfico 1, que os clíticos reflexivos e reciprocos, conforme supúnhamos, são mais propensos ao uso na comunidade por nós investigada. Tal propensão justifica-se pelo fato de os reflexivos e recíprocos serem os clíticos que possuem mais valor informacional (são argumentais e estabelecem com o sujeito sintático uma relação de coindexação e correferencialidade). Vejam-se os exemplos a seguir:

(20) A gente se gosta muito, a gente... a gente conversa muito, a gente lê muito junto. (AI - PCVC - III - F)

(21) eu acho que o povo de Conquista se veste bem, no geral, né (DFP - PCVC - I - F)

(22) eu preciso ganhá um salário que pra eu assim, pra mim comprá rôpa e sapato pra eles, as coisa pra eles se mantê_(E.S.P.,PPVC,II,F)

Por meio dos exemplos em (20) a (22), percebe-se que os clíticos do tipo reflexivo e recíproco são essenciais à estrutura da qual fazem parte e, portanto, sua supressão comprometeria o sentido

\footnotetext{
14 "Um nocaute [...] é um fator que, num dado momento da análise, corresponde a uma frequência de $0 \%$ ou de $100 \%$ para um dos valores da variável dependente [...]” (GUY; ZILLES, 2007, p.158).
} 
do enunciado. Como são os que mais possuem valor informacional, são também os que apresentam maior peso relativo - 0,77 para o reflexivo e 0,70 para o recíproco.

Constituindo o grupo não-reflexivo, os demais tipos de SE, com menor valor informacional, foram os que se mostraram mais sensíveis ao apagamento. Segundo nossas expectativas, os clíticos inerentes apareceriam numa posição intermediária, por força das especificações lexicais do verbo, o qual integrariam como afixos. Contudo, um peso relativo de 0,46 para os indeterminadores, em detrimento de um menor valor gerado para os inerentes - 0,35, não correspondeu à ordem de aplicação que supúnhamos. Ambos os valores, no entanto, associados ao peso de 0,32 gerado para os expletivos, situaram-se abaixo do ponto neutro, indicando que são menos produtivos no vernáculo conquistense.

Dentre os clíticos do grupo não-reflexivo, os indeterminadores são os que mais se aproximam do ponto neutro. O peso relativo de 0,46 é um indicativo de que o SE, lado a lado de sua variante nula, vem ganhando robustez entre as estratégias de indeterminação do sujeito/agente disponíveis no PB. Em consonância com Mello (2009), postulamos que essa tendência se configura um indício de mudança incipiente, enveredando-se para um estágio mais avançado do processo de gramaticalização do SE, consoante demonstram os exemplos de presença e ausência de SE indeterminador a seguir, em dados dos nossos corpora:

(23) Hoje não se pode fazê fogueira em qualqué rua, isso aí não $\emptyset$ pode fazê mesmo (AIPCVC-III-F)

(24) a adrenalina que $\boldsymbol{\varnothing}$ tinha com esse meter medo, com o medo que se metia, era maravilhosa. (AI-PCVC-III-F)

(25) eu acho ah... ah... o tipo de brincadera dinâmica, de brincadera atual, ela possibilita uma...um desenvolvimento cognitivo é... em algumas áreas melhor mas em outras eu acho que... que... em outros casos há prejuízos né... então eu acho que perde-se e ganha Ø (HFS-PCVC-II- M)

Em (23) a (25), tanto a presença quanto o apagamento do SE observáveis na fala do mesmo informante, num mesmo turno conversacional, remetem ao princípio da estratificação ${ }^{15}$ (HOPPER, 1991). Essas ocorrências constituem uma evidência a mais de que as variantes preenchida e nula, não apenas de um, mas de todos dos tipos de SE selecionados nesta pesquisa coexistem em um mesmo domínio linguístico. Quanto aos clíticos expletivo e apassivador, embora não tenham apresentado relevância estatística, não significa que estejam à margem dos fenômenos de mudança que atingem o pronome reflexivo no $\mathrm{PB}$. Como não absorvem argumento e nem recebem caso, possuem baixo valor informacional, logo, tornam-se cada vez menos frequentes, restando-lhes duas vias: ou se especializam como afixos verbais ou desaparecem. Sem dúvida, uma consequência da dessemantizạ̧ão (HOPPER; TRAUGOTT, 1993) desses clíticos, ou seja, da perda de seu conteúdo semântico.

\subsection{Classe semântica do verbo}

Para o controle do fator classe semântica do verbo, tomamos por base a tipologia de Kemmer (1993), feitas algumas modificações. Além das dez classes semânticas propostas pela autora,

\footnotetext{
15 Pelo princípio da estratificação (cf. HOPPER, 1991), camadas diferentes (novas e antigas) podem coexistir em um mesmo domínio funcional, como resultado da gramaticalização. Visto pelo prisma da Sociolinguística Variacionista (cf. TAVARES, 2013, P. 29), o mesmo fenômeno é concebido como variação linguística, nos termos de Labov (2008[1972]), em que formas variantes (conservadoras e inovadoras) coexistem na língua para fazer referência a um mesmo significado. É o caso, por exemplo, da alternância SE/Ø nas funções exercidas pelo clítico. Em um mesmo contexto, convivem tanto a presença quanto o apagamento da forma, mantendo-se o mesmo significado, conforme ilustrado em (23) a (25).
} 
adotamos aquelas acrescentadas por Pereira (2007) à lista, a saber: outros atos de fala e passiva e impessoal. Ademais, e em consonância com os dados desta pesquisa, agregamos outras duas classes: verbos de estado/mudança de estado e outros. Também substituímos a classe passiva e impessoal por indeterminação do agente, de modo que o quadro apresentado a seguir se configura uma adaptação das propostas de Kemmer (1993) e Pereira (2007). Vejamos:

\begin{tabular}{|c|c|c|}
\hline Classe semântica & Definição & Exemplos \\
\hline \begin{tabular}{l|l} 
1.Cuidado \\
corporal.
\end{tabular} & $\begin{array}{l}\text { Ações executadas pelo indivíduo } \\
\text { nele mesmo. }\end{array}$ & $\begin{array}{ll}\text { - } & \text { Banhar-se } \\
\text { - } & \text { Barbear-se } \\
\text { - } & \text { Lavar-se } \\
\end{array}$ \\
\hline $\begin{array}{l}\text { 2.Movimento não } \\
\text { translacional. }\end{array}$ & $\begin{array}{l}\text { Mudança na configuração do } \\
\text { corpo sem mudar a sua } \\
\text { localização. }\end{array}$ & $\begin{array}{ll}\text { - } & \text { Abaixar-se } \\
\text { - } & \text { Esticar-se } \\
\text { - } & \text { Inclinar-se } \\
\end{array}$ \\
\hline $\begin{array}{l}\text { 3.Mudança na } \\
\text { postura corporal. }\end{array}$ & $\begin{array}{l}\text { Mudança na configuração do } \\
\text { corpo em relação a uma } \\
\text { localização. }\end{array}$ & $\begin{array}{ll}\text { - } & \text { Ajoelhar-se (no altar) } \\
\text { - } & \text { Deitar-se (na cama) } \\
\text { - } & \text { Levantar-se (do sofá) } \\
\end{array}$ \\
\hline $\begin{array}{l}\text { 4.Movimento } \\
\text { translacional }\end{array}$ & Movimento através do espaço. & $\begin{array}{ll}\text { - } & \text { Aproximar-se } \\
\text { - } & \text { Distanciar-se } \\
\text { - } & \text { Mover-se } \\
\end{array}$ \\
\hline $\begin{array}{l}\text { 5.Média de } \\
\text { emoção }^{16}\end{array}$ & $\begin{array}{l}\text { Processos/estados mentais } \\
\text { emotivos }\end{array}$ & $\begin{array}{ll}\text { - } & \text { Alegrar-se } \\
\text { - } & \text { Consolar-se } \\
\text { - } & \text { Satisfazer-se }\end{array}$ \\
\hline $\begin{array}{l}\text { 6.Média de } \\
\text { cognição }\end{array}$ & $\begin{array}{l}\text { Processos/estados mentais } \\
\text { cognitivos }\end{array}$ & $\begin{array}{ll}\text { - } & \text { Decidir-se } \\
\text { - } & \text { Esquecer-se } \\
\text { - } & \text { Dar-se } \\
\end{array}$ \\
\hline $\begin{array}{l}\text { 7.Ato de fala } \\
\text { emotivo }\end{array}$ & Ato de fala de natureza emotiva & $\begin{array}{ll}\text { - } & \text { Gabar-se } \\
\text { - } & \text { Lamentar-se } \\
\text { - } & \text { Vangloriar-se } \\
\end{array}$ \\
\hline $\begin{array}{l}\text { 8. Outros atos de } \\
\text { fala }\end{array}$ & $\begin{array}{l}\text { Atos de fala de natureza } \\
\text { declarativa }\end{array}$ & $\begin{array}{ll}\text { - } & \text { Confessar-se } \\
\text { - } & \text { Culpar-se } \\
\text { - } & \text { Declarar-se } \\
\end{array}$ \\
\hline 9.Média indireta & $\begin{array}{l}\text { A entidade agente é comumente } \\
\text { ou necessariamente o participante } \\
\text { recipiente ou beneficiário da ação }\end{array}$ & $\begin{array}{l}\text { - } \\
\text { - Apropriar-se } \\
\text { Apossar-se }\end{array}$ \\
\hline $\begin{array}{l}\text { 10.Eventos } \\
\text { naturalmente } \\
\text { recíprocos }\end{array}$ & $\begin{array}{l}\text { Ações ou estados em que a } \\
\text { relação entre os participantes é } \\
\text { normalmente ou } \\
\text { necessariamente mútua }\end{array}$ & $\begin{array}{l}\text { - Abraçar-se } \\
\text { - Casar-se } \\
\text { - Cumprimentar-se } \\
\end{array}$ \\
\hline $\begin{array}{l}\text { 11.Eventos } \\
\text { espontâneos. }\end{array}$ & $\begin{array}{l}\text { Processos que tipicamente são } \\
\text { percebidos como ocorrendo sem } \\
\text { a iniciação direta de um agente }\end{array}$ & $\begin{array}{ll}\text { - } & \text { Criar-se } \\
\text { - } & \text { Desenvolver-se } \\
\text { - } & \text { Originar-se } \\
\end{array}$ \\
\hline
\end{tabular}

16 Verbos dessa classe são mencionados tanto por linguistas quanto por gramáticos da Língua Portuguesa. Said Ali (1966), por exemplo, ressalta que em aborrecer-se, admirar-se, excitar-se, arrepender-se, não compreendemos a pessoa como agindo sobre si mesma (ação reflexiva). O que se expressa, em vez disso, é um sentimento, indicando que a pessoa está vivamente afetada por algo (cf. também BECHARA, 1980, 2001). 


\begin{tabular}{|l|l|l|}
\hline $\begin{array}{l}\text { 12.Indeterminação } \\
\text { do Agente/ }\end{array}$ & $\begin{array}{l}\text { Ações ou processos que } \\
\text { envolvem um agente não } \\
\text { expresso. }\end{array}$ & $\bullet$ Isso não se diz \\
\hline $\begin{array}{l}\text { 13. Estado/ } \\
\text { mudança de estado }\end{array}$ & $\begin{array}{l}\text { Engloba basicamente o verbo } \\
\text { chamar e os copulativos }\end{array}$ & $\begin{array}{l}\bullet \text { Chamar-se } \\
\bullet \text { Tornar-se } \\
\text { - Transformar-se }\end{array}$ \\
\hline 14. Outros & $\begin{array}{l}\text { Associação com o clítico constitui } \\
\text { expressão cristalizada }\end{array}$ & $\begin{array}{l}\text { - Foda-se } \\
\text { - Dane-se }\end{array}$ \\
\hline
\end{tabular}

Quadro 1 - Classes semânticas do verbo

Fonte: KEMMER (1993); PEREIRA (2007), adaptado.

Considerado o segundo fator linguístico de maior significância pelo programa estatístico, a variável classe semântica do verbo, em pesos relativos, pode ser visualizada a partir do Gráfico 2 a seguir:

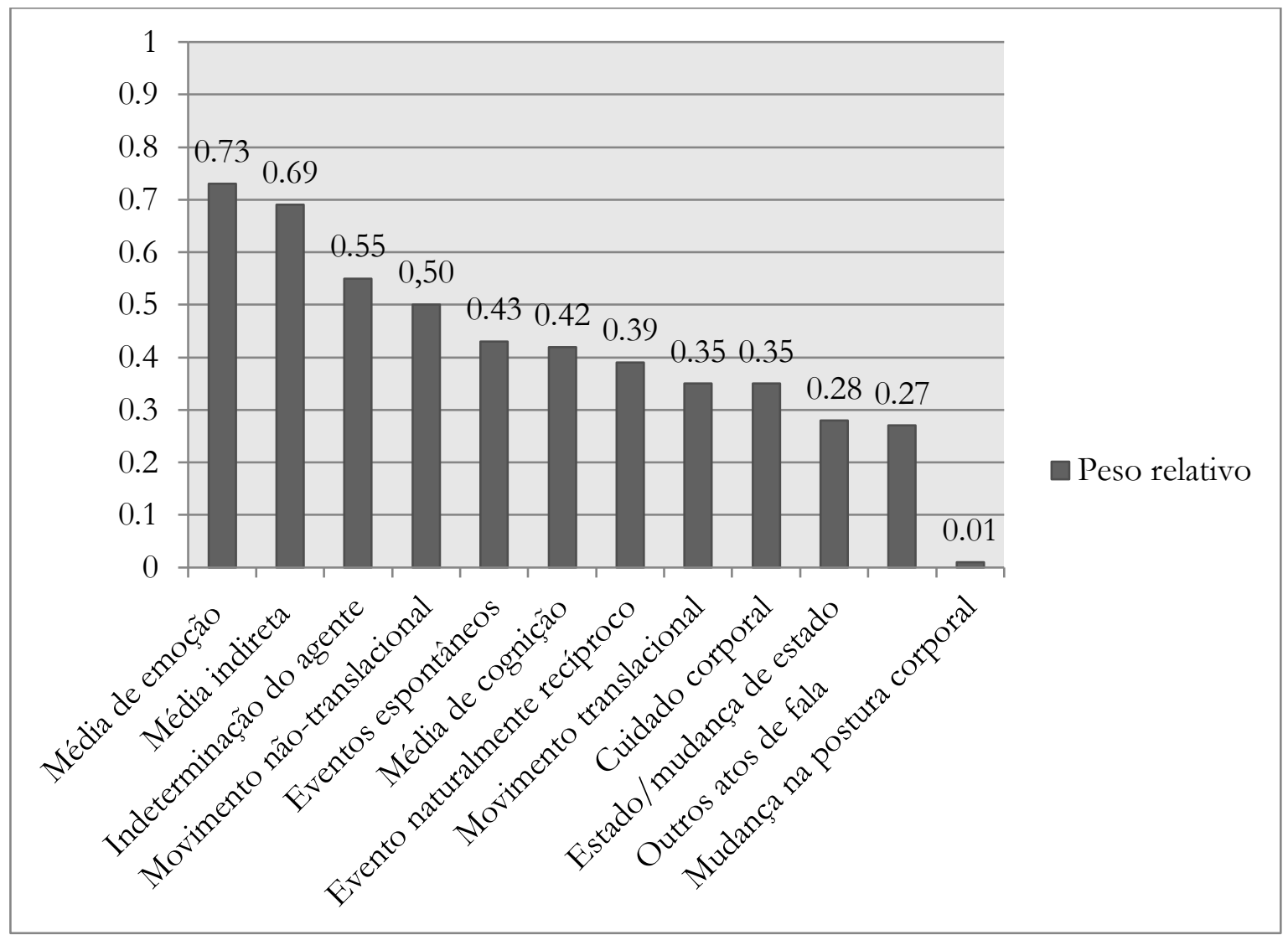

Gráfico 2 - Classe semântica do verbo nos corpora PPVC e PCVC em pesos relativos

Fonte: Elaboração da pesquisadora

Em relação a esta variável, os fatores média de emoção $(0,73)$, média indireta $(0,69)$ e indeterminação do agente $(0,55)$ são aqueles que mais favorecem a aplicação da regra de presença do clítico. A classe movimento não-translacional encontra-se exatamente no ponto neutro $(0,50)$ e as demais, pelo baixo valor atribuído, revelam-se contextos menos favorecedores do uso do SE, conforme demonstrado na Gráfico 2.

${ }_{17}$ Incluímos nesse fator verbos que não se encaixam na classificação de Kemmer (1993). 
Com base em Kemmer (1993), a nossa hipótese para o grupo de fatores em análise era a seguinte: se uma língua apresenta variação entre duas formas pronominais [presença vs apagamento], aquela fonologicamente mais pesada e independente será favorecida nos contextos de reflexividade e reciprocidade propriamente ditas, ao passo em que a forma fonologicamente mais leve (ou nula) tenderá a ser utilizada em estruturas médias. Os índices encontrados, no entanto, revelam uma tendência de realização do SE em construções médias, conforme apontam os valores refletidos nos pesos relativos $0,73,0,69$ e 0,55 , respectivamente, para os fatores média de emoção, média indireta e indeterminação do agente.

Os nossos dados revelam que, nos contextos em que o SE é argumental, (classes semânticas cuidado corporal, movimento não-translacional, mudança na postura corporal e movimento translacional), ele tende a ser omitido, enquanto que a manutenção do clítico é favorecida nas situações linguísticas onde não mais expressa reflexividade - razão da superioridade numérica do SE em contextos mediais. Conclui-se, portanto, que fatores semânticos como a conotação emotiva de uma expressão ou a existência (necessária ou não) de um agente exercem forte influência no uso da forma, como se pode perceber nas ocorrências em (26) a (28):

(26) E eu gosto também eh, assim, vê que uma pessoa se sente bem perto de você e você faz bem àquela pessoa assim. (JLS-PCVC- I-M)

(27) Ah... minha mãe é... uma pessoa é... que muito cuidadosa com os filhos né, que sempre se preocupou que sempre é... acompanhou a educação... né se esforçou pra que nós estudássemos o máximo possível. (HFS-PCVC-II- M)

(28) Aí ela foi lá né, ele achô que era eu que ia, né, e aí se empolgô todo e foi pra esse encontro, chegou lá tava ela. Mar môss, nesse dia foi um péga pá capá, viu, a gente ficô de mal mar de dois meses, foi mesmo... (SJS-PPVC-I-F)

$\mathrm{Na}$ subseção a seguir, apresentamos os resultados das varáveis sociais selecionadas: escolaridade e faixa etária.

\subsection{Escolaridade}

A variável escolaridade, para cuja composição tomamos os fatores popular e culto, de acordo com os níveis de escolaridade dos informantes, foi a primeira variável social selecionada pelo programa estatístico e considerada, também, a de maior significância. A análise dessa variável nos permite verificar como o falante do Português Popular e do Culto se comportam em relação ao (des)uso do clítico SE em Vitória da Conquista. Destarte, assume papel importante no estudo que ora empreendemos. Neste aspecto específico, os resultados são bastante expressivos, porquanto estamos lidando com a presença vs o apagamento do SE, na perspectiva das práticas de letramento a que o informante teve ou não acesso. Isto posto, observe-se o gráfico - 3, a seguir, no qual apresentamos os resultados da variável: 


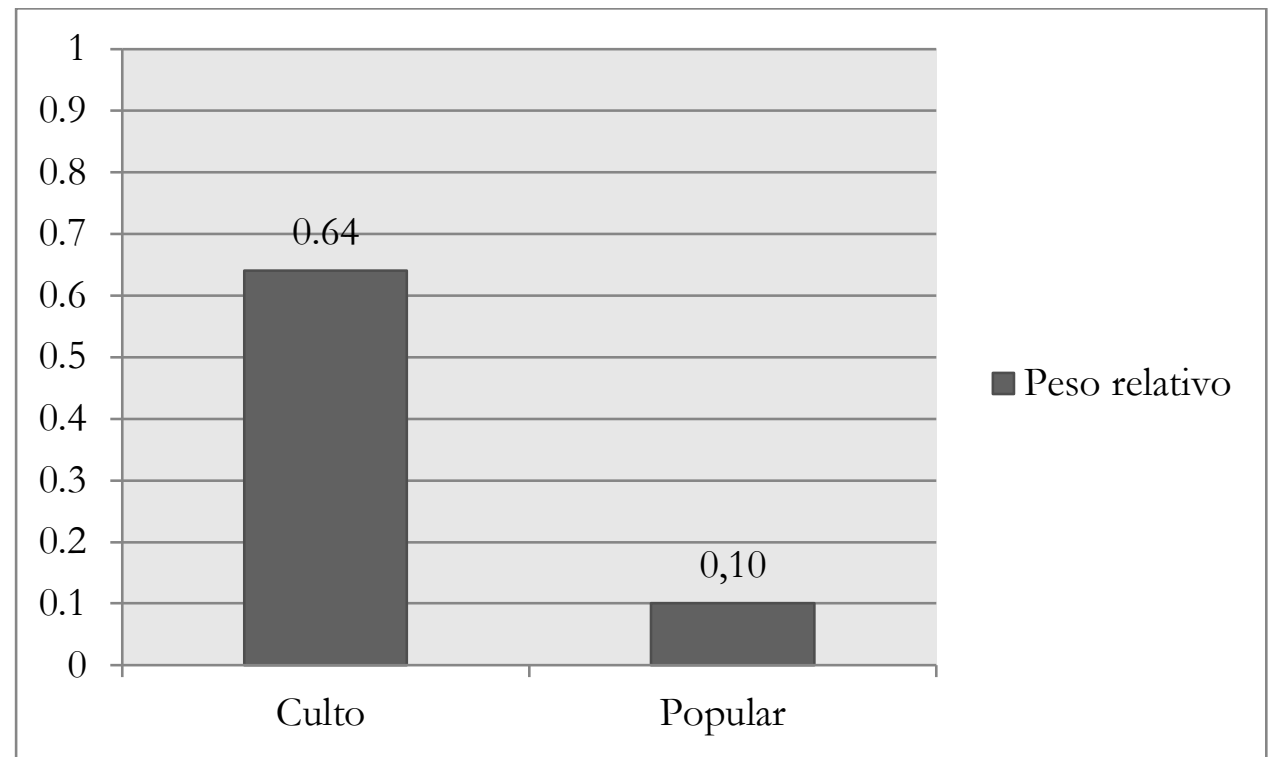

Gráfico 3 - Escolaridade nos corpora PPVC e PCVC em pesos relativos Fonte: Elaboração da pesquisadora

O peso relativo mais expressivo encontra-se no fator culto. Evidentemente, o segmento de informantes mais escolarizados, cujo peso relativo é de 0.64 , figura como o fator que mais influencia a presença do SE, em oposição ao fator popular, que compreende informantes menos escolarizados, refletido num peso de apenas 0,10.

Conforme prevíamos, os resultados obtidos confirmam que os informantes do PCVC tendem mais ao uso do SE, sugerindo que a inserção do clítico no repertório linguístico do falante de Vitória da Conquista se dá, sobretudo, por influência do processo de escolarização. A esses resultados, atribuímos também o fato de o apagamento ser perspectivado com certo grau de censura, o que nos leva a vislumbrar o uso do SE na esfera do que Labov (1980) chama de "marcador" - traço linguístico social e estilístico que suscita efeitos consistentes sobre o julgamento (consciente ou inconsciente) do ouvinte sobre o falante.

\subsection{Faixa etária}

Por meio desta variável, é possível vislumbrar a direção do fenômeno e, a partir daí, diagnosticar uma mudança em curso ou se os dados não a indicam. No tocante ao SE em Vitória da Conquista, se o apagamento do clítico poderá vir a se firmar ou se o uso há de prevalecer. Os resultados desta variável são expressos no Gráfico 4:

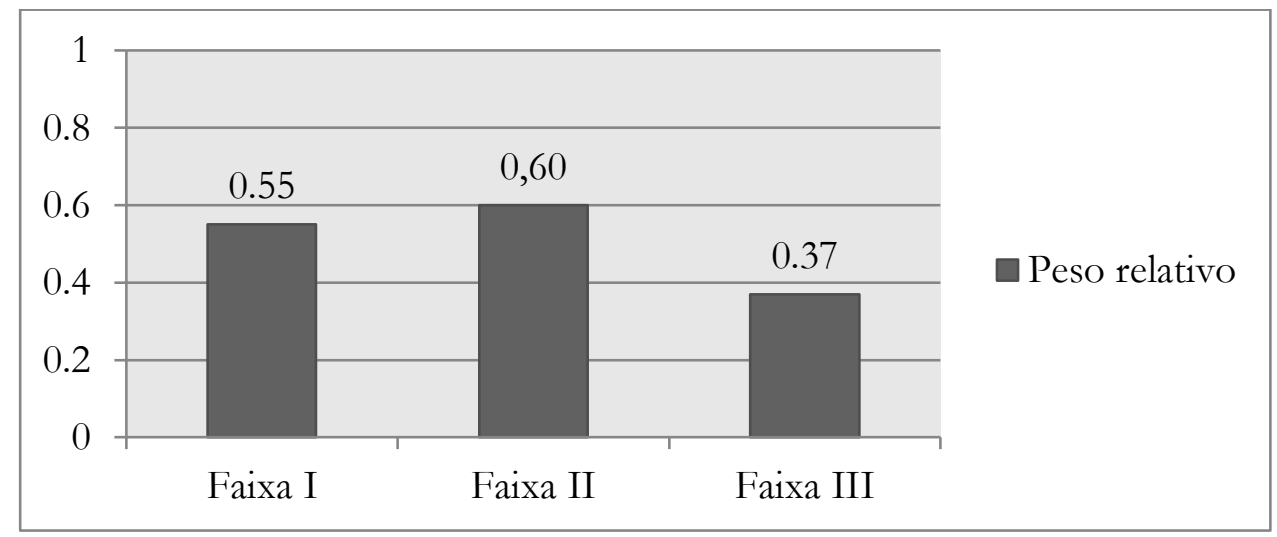

Gráfico 4 - Faixa etária nos corpora PPVC e PCVC em pesos relativos

Fonte: Elaboração da pesquisadora 
Supúnhamos que a faixa II representasse o ponto neutro quanto ao (des)uso do SE. Influenciados por Monteiro (1994, p. 178), para quem “[...] os clíticos aparecem um pouco mais na fala dos mais idosos", esperávamos que a presença da forma fosse favorecida na faixa III, ao passo que o favorecimento ao apagamento, por seu turno, ocorresse entre os jovens. Os resultados mostram, no entanto, que são os informantes da faixa etária intermediária, com peso relativo de 0,60, os mais propensos ao uso do SE. Próximos ao ponto neutro estão os falantes mais jovens, cujo peso relativo é de 0,55 , indicando, assim, uma certa estabilidade quanto à aplicação da regra. Curiosamente, o e peso de 0,37, atribuído à terceira faixa, mostra que os informantes mais velhos são os que mais apagam o SE, quando a tendência geral, conforme sublinha Tavares (2003), é a de que novos usos de uma forma sejam mais recorrentes entre indivíduos mais jovens. Para esses achados, damos como explicação a influência da escola na manutenção das formas de prestígio. Aventamos, assim, a possibilidade de os informantes mais jovens serem aqueles que possuem maior oportunidade de escolarização. Por força do papel regulador da instituição escolar, tendem, portanto, a manter mais o clítico.

Destarte, os valores apresentados no Gráfico 4 nos permitem observar que o uso do SE é bastante produtivo no falar de Vitória da Conquista - BA, em especial entre os falantes da Faixa II, para cujo grupo os pesos relativos apontam maior frequência, em razão do "equacionamento" e relativização das variáveis controladas e selecionadas, após submetidas ao programa estatístico.

\section{CONSIDERAÇÕES FINAIS}

Neste trabalho, analisamos e descrevemos o funcionamento do clítico SE em estruturas tradicionalmente classificadas como reflexivas na fala de informantes do Português Popular e do Culto de Vitória da Conquista - BA, levando em consideração fatores linguísticos e sociais que influenciariam a realização da variável.

Os números apontaram o uso, em detrimento do apagamento do SE, como a preferência dos conquistenses. Das 617 ocorrências selecionadas, 489 apresentaram o clítico adjungido ao verbo, enquanto que em 128 delas, foi apagado. Em valores percentuais, identificou-se um total de $79,3 \%$ de presença contra $20,7 \%$ de apagamento da forma. Em relação ao condicionamento linguístico, o uso do SE mostrou-se sensível ao tipo de clítico, tendo apresentado a gradação de uso $S E$ reflexivo $>S E$ recíproco $>S E$ inerente $>S E$ indeterminador $>S E$ ergativo, e à classe semântica do verbo, demonstrando que os tipos média de emoção, média indireta e indeterminação do agente são os que mais favorecem a presença do clítico junto ao verbo. No que respeita ao condicionamento social, a presença do SE é mais favorecida entre os informantes mais escolarizados e da faixa etária intermediária.

Os nossos resultados indicam que o clítico SE tem seu uso expandido no falar de Vitória da Conquista. Ao ampliar o seu contexto de ocorrências, o SE vai se tornando cada vez mais opaco, deixando, assim, a sua função primeira de estabelecer correferencialidade entre o sujeito e o objeto e assumindo novas nuanças, menos concretas. Se vai atingir o Estágio Zero do processo, desaparecendo da língua, não podemos precisar ainda. O que se pode afirmar, até então, é que estamos lidando com um fenômeno que impulsiona um incessante ciclo de mudança via gramaticalização: um SE que "nasce" de uma função e, em seguida, encerra várias outras. Algumas delas, mais frequentes na língua; outras, caindo em desuso.

Isto posto, esperamos, com este trabalho, contribuir para ampliar o cenário nacional dos estudos linguísticos acerca da temática por nós abordada, sobretudo na Região Nordeste do país. 


\section{REFERÊNCIAS}

BARBOZA, Jerónymo Soares. GrammaticaPhilosophica da LinguaPortugueza. Lisboa: Typographia da Academia de Lisboa, 1830.

BARROS, João de. Grammatica da lingua portuguesa - Olyssipone - apud LodouicumRotorigiu[m], Typographum, 1540.

BECHARA, Evanildo. Moderna gramática portuguesa. Edição Revista e Ampliada. 37. ed., Rio de Janeiro: Lucerna, 2004[1966].

BRITO, Ana Maria; DUARTE, Inês; MATOS, Gabriela. Tipologia e Distribuição das Expressões Nominais. In: MATEUS, Maria Helena Mira et al. Gramática da Lingua Portuguesa. Lisboa: Editorial Caminho, 2003, 795-867.

BYBEE, Joan; PERKINS, Revere; PAGLIUCA, William. The evolucion of grammar: tense, aspect, and modality in the language of the world. Chicago: The Universityof Chicago Press, 1994.

CAMACHO, Roberto Gomes. Em defesa da voz média no português. Delta, São José do Rio Preto (SP). n. 19: 1. p. 91-121, 2003.

CÂMARA JR, Joaquim Mattoso. Princípios de lingüística geral como introdução aos estudos superiores da língua portuguesa. 5. ed. Rio de Janeiro: Ed. Padrão, 1974.

CARVALHO, Castelar de. O pronome se: uma palavra oblíqua e dissimulada. [Tese de doutorado em Linguística]. Rio de Janeiro: UFRJ, 1990.

CASTILHO, Ataliba Teixeira de. Nova Gramática do Português Brasileiro. São Paulo: Contexto, 2016.

CHOMSKY, Noam. Knowledge of Language, Its Nature, Origin and Use. New York: Praeger Publishers, 1986.

CUNHA, Celso Ferreira da. Gramática da Lingua Portuguesa. 11 ed. Rio de Janeiro: FAE, 1986.

D'AlBUQUERQUE, Alair da Cruz Reis Cavalcanti. A perda dos clíticos em um dialeto mineiro. Revista Tempo brasileiro: sociolingüística e o ensino do vernáculo. Rio de Janeiro: Tempo brasileiro, 1988, p. 97-121.

DIAS, Epiphanio Silva. GrammaticaPortugueza Elementar. Lisboa: A. Ferreira Machado Editores, 1881.

FREITAG, Raquel Meister Ko. Uma hipótese de gramaticalização do pronome reflexivo se na fala de Florianópolis. Working papers em Lingü̈stica, n 7. Florianópolis, CPGLg, 2003.

GALVES, Charlotte. Ensaios sobre as gramáticas do português. Campinas: Ed. UNICAMP, 2001.

GIVÓN, Talmy. Syntax: a functional-typological introduction. v. 1. Amsterdam/Philadelphia: John Benjamins Publishing Co., 1984. 
GUY, Gregory Riodan; ZILLES, Ana. Sociolinguistica quantitativa - instrumento de análise. São Paulo: Parábola Editorial, 2007.

HOPPER, Paul. On some principles of grammaticization. In: TRAUGOT'T, Elizabeth.; HEINE, Bernd (Eds.). Approaches to grammaticalization. Amsterdam: John Benjamins, 1991. p. 17- 36.

HOPPER, Paul.; TRAUGOTT, Elizabeth. Grammaticalizacion. Cambridge: Cambridge University Press, 1993.

ILARI, Rodolfo et. al. Os pronomes pessoais do Português Falado: roteiro para análise. In.: CASTILHO, Ataliba Teixeira de; BASÍLIO, Margarida. Gramática do Português Falado: estudos descritivos. Vol. IV. 2. ed. rev. Campinas: Editora da UNICAMP, 1996.

KAYNE, Richard. (1975). French Syntax - The Transformational Cycle. Cambridge, Massachusetts: The MIT Press.

KEMMER, Suzanne. The middle voice. Amsterdam/Philadelphia: JonhBenjamins Publishing Company, 1993.

LABOV, William. Padrões sociolingüísticos. Trad. de M. Bagno; M. M. P. Scherre; C. R. Cardoso. São Paulo: Parábola Editorial, 2008 [1972].

MATTOS E SILVA, Rosa Virgínia. Tradição gramatical e gramática tradicional. São Paulo: Contexto, 1989.

MELLO, Fernanda Rosário de. "Acabou-se o que era doce. Quem comeu se regalou-se": Uma análise do clítico se em João Pessoa na interface Sociolinguística/Gramaticalização. 322f. Tese (Doutorado em Linguística). Universidade Federal da Paraíba, João Pessoa, 2009.

MONTEIRO, José Lemos. Pronomes pessoais: subsidios para uma gramática do português do Brasil. Fortaleza: Edições UFC, 1994.

NUNES, Jairo. Ainda o famigerado se. D.E.L.T.A., v.11, n.2, p.201-240, 1995.

OLIVEIRA, Marilza de. Nós se cliticiz̧ou-se?. In: LOBO, Tânia Conceição Freire et al. Para a história do português brasileiro . Salvador : EDUFBA, 2006. v. 6, t. 1-2. P. 413-424.

PEREIRA, Ana Luiza Dias. Os pronomes clíticos do PB contemporâneo na perspectiva teórica da Morfologia Distribuida. 204f. Tese (Doutorado em Linguística). Universidade Federal de Santa Catarina, Florianópolis, 2006.

ROCHA LIMA, Carlos Henrique da. Gramática Normativa da Lingua Portuguesa. Rio de Janeiro: José Olympio Editora, 2003.

ROCHA, Angela de Fátima. Clíticos reflexivos: uma variante sociolingü̈stica na cidade de Ouro Preto. Dissertação de Mestrado. Belo Horizonte: UFMG, 1999.

SAID ALI, Manuel. Dificuldades da lingua portuguesa. 6. ed. Rio de Janeiro: Acadêmica, 1966. 
SANKOFF, David; TAGLIAMONTE, Sali; SMITH, Eric. Goldvarb X: um aplicativo de regra variável para Macintosh e Windows. Departamento de Linguística, Universidade de Toronto, 2005.

SCHERRE, Maria Marta Pereira; NARO, Anthony. Julius. Análise quantitativa e tópicos de interpretação do Varbrul. In: MOLLICA, Maria Cecília; BRAGA, Maria Luiza. (Orgs.). Introdução à Sociolinguística: o tratamento da variação. Editora Contexto, São Paulo-SP, 2012, p.147-177.

TAVARES, Maria Alice. A gramaticalização de e, daí, aí, então: estratificação/variação e mudança no dominio funcional da seqüenciação retroativo-propulsora de informações - um estudo sociofuncionalista. (Tese de Doutorado). Florianópolis: UFSC, 2003.

Sociofuncionalismo: um duplo olhar sobre a variação e a mudança linguística. Interdisciplinar-Revista de Estudos em Lingua e Literatura, vol. 17, p. 27-48, 2013.

ZWICKY, Arnold. On clitics. Bloomington: Indiana University Linguistics Club, 1977. 